\title{
MEASUREMENTS AND ANALYSES OF VELOCITY PROFILES AND FRAZIL ICE-CRYSTAL RISE VELOCITIES DURING PERIODS OF FRAZIL-ICE FORMATION IN RIVERS
}

by

\author{
J. P. Gosink and T. E. Osterkamp \\ (Geophysical Institute, University of Alaska, Fairbanks, Alaska 99701, U.S.A.)
}

\section{ABSTRACT}

The vertical concentration distribution of frazil-ice crystals in a stream during the formation and growth of frazil ice was discussed in a preliminary way by Gosink and 0sterkamp (1981). This paper extends and completes the analysis of buoyant rise velocities of frazil-ice crystals and applies the results to an interpretation of measured velocity profiles in rivers during frazil-ice events. Additional experimental data are also presented. Two tiwe scales are defined: the buoyant time scale $T_{B}$, which represents the tilie required for a frazil crystal to rise, buoyantly, froin the river bottom to the water surface, and the diffusive time scale $T_{0}$, which represents the time required for a frazil crystal to be transported by turbulence through the depth. It is shown that the ratio of the time scales $T_{B} / T_{D}$ defines the nature of the layering processes; in particular, if $T_{B} / T_{D}<1$, then buoyant forces will lift a frazil crystal faster than turbulent diffusion can redistribute it and the flow will be layered. Conversely, if $T_{B} / T_{D}>1$, turbulent mixing will proceed faster than buoyant lifting and the flow will be well-mixed. This ratio, for frazil particles of diameter 2 ini or more, corresponds to rule-of-thumb velocity criteria developed in Norway and Canada to distinguish Tayered frazil-ice/water flow from wellmixed flow.

The development of this theory depends in large part upon the determination of $T_{B}$, which depends upon the rise velocity of frazil-ice crystals. A force balance nodel was developed for the rise velocity of a frazil crystal. Field observations during frazilice formation in Goldstream Creek and in the Chatanika River north of Fairbanks are reported, including a series of measurements of the rise velocities of frazil-ice crystals. Typical particle size of frazil ice was about $2 \mathrm{~mm}$ with a rise velocity of about $10.0 \mathrm{~mm} \mathrm{~s} \mathrm{~s}^{-1}$. The agreement of measured rise velocities with the theoretical model is good considering uncertainties in the drag coefficient and in the determination of frazil crystal sizes under field conditions.

Velocity profiles in the Chatanika River and in Goldstreain Creek during frazil formation suggest that the time-scale ratio may serve as a transition criterion between layered frazil-ice/water flow and wellmixed flow. This ratio was calculated with the rise velocity of frazil-ice crystals arbitrarily chosen to be $0.01 \mathrm{~m} \mathrm{~s}^{-1}$.

\section{INTRODUCTION}

Observations of ice formation in northern rivers during the freeze-up period show that three ice-flow regimes are common: sheet ice, floating frazil ice and a well-mixed flow (frazil-ice crystals and water). In the last case, if the velocity of the river is sufficiently high, open water conditions may persist throughout the winter.

Designers of hydraulic structures such as canals, water transportation facilities, hydroelectric power structures, water-intake structures, etc., may require information on which flow regime to expect under a given set of flow conditions and on the transition from an ice cover to open water flow. Thus, there is substantial interest in developing criteria which can be used to predict the conditions that lead to each of these three flow regimes and the presence or absence of an ice cover.

It could be argued that the criteria for the transition from floating frazil ice to a well-mixed flow should be the same as the criteria for the formation of an ice cover. The reason for this is that if the frazil crystals remain mixed with the flow then they cannot accumulate on the surface to form an ice cover. However, it is clear that other hydrological aspects of rivers enter into criteria on the presence or absence of an ice cover. These include the sinuosity, channel and slope variability, bed roughness and also the mechanics of frazil crystal, floc, pan and floe interactions (Osterkamp and Gosink in press) and changes of these parameters during the growth of an ice cover.

For many locations, rule-of-thumb flow velocities have been determined, which define the transitions from well-mixed flow to floating frazil ice and the formation of a coherent ice cover. For example, in Norway (where rivers are often wide, shallow, with steep slopes and underlain with rocks or boulders), the water surface is usually covered with moving frazil slush if the water velocity is $>0.6$ and $<1.2 \mathrm{~m} \mathrm{~s}^{-1}$, and open if the water velocity is $>1.2 \mathrm{~m} \mathrm{~s}^{-1}$ (Carstens 1971). On the Saint Lawrence Waterway in Canada layered frazil-ice flow may be expected at river velocities $>0.8$ and $<1.0 \mathrm{~m} \mathrm{~s}^{-1}$, 
and at velocities $>1.0 \mathrm{~m} \mathrm{~s}^{-1}$ the river surface usually remains free of ice (Starosolszky 1971). However, these empirical formulations are known to be imprecise as the critical velocity varies with water depth, bottom roughness and meteorological conditions. In particular, Bengtsson (1982) reports icefree conditions on the Råne river in Sweden where flow velocity was $<0.6 \mathrm{~m} \mathrm{~s}^{-1}$ and flow depth was $<0.5 \mathrm{~m}$. Carstens (1971) claims that the transition river velocity is reduced for flow depths $>5.0 \mathrm{~m}$. Studies in Hokkaido, Japan (Hirayama 1982), suggest that river slope is another important parameter for the maintenance of ice-free conditions. Matousek (1982) prescribes a formula for that velocity "at which all clusters of ice crystals still float on the surface". Unfortunately, no derivation for the formula nor comparison with data is given.

If frazil-ice crystals rise to the water surface faster than they are renoved by turbulent mixing, a two-layer flow will result. Gosink and 0sterkamp (1981) have proposed a criterion for layered vs wellmixed flow which depends upon competing time scales for buoyancy and vertical turbulent diffusion. The buoyancy time scale $T_{B}$ is the time required for a frazil-ice crystal to rise the depth of the stream, and is given by $T_{B}=h / V$ where $h$ is the steam depth and $V$ is the rise velocity of a frazil-ice crystal. The time scale for turbulent diffusion $T_{D}$ is determined from the friction velocity of the stream according to standard vertical mixing theory for open channel flow. The ratio of these competing time scales $T_{B} / T_{D}$ defines the nature of the layering process; if $T_{B} / T_{D}<1$, buoyant forces will 1 ift a particle of frazil ice faster than turbulent diffusion can redistribute it and the flow will be layered, and, if $T_{B} / T_{D}>1$, turbulent mixing will proceed faster than buoyant lifting and the flow will be well-mixed.

This paper presents results of field and laboratory measurements of the rise velocity of frazil-ice crystals and of the velocity profiles in turbulent streams during periods of frazil-ice production. Data on rise velocities are compared with a simple theoretical model. The velocity profiles were analyzed to determine the suitability of a time-scale ratio as a criterion for the transition from layered to wellmixed flow.

\section{RISE VELOCITIES}

Experimental

The field experiments to measure rise velocities of frazil-ice crystals were performed during freezeup in October 1981 in the Chatanika River north of Fairbanks. A transparent, graduated cylinder about $0.45 \mathrm{~m}$ long and $0.08 \mathrm{~m}$ in diameter was used to scoop water laden with frazil ice from the river. The cylinder was imriediately set upright on a table and the motion of the crystals of frazil ice was observed. Velocities were measured by timing the displacement of the frazil particles past the graduations on the cylinder. I ce-crystal diameters were estimated by comparison with these graduations. Generally individual particles could be observed over displacement distances of at least $0.1 \mathrm{~m}$. For a rise velocity of $10 \mathrm{~mm} \mathrm{~s}-1$, this suggests an observation period of $10 \mathrm{~s}$.

Each measured rise velocity is shown as a function of ice-crystal diameter in Figure 1. The inaccuracy involved in the estimate of dianeter may account for some of the scatter in the data. However, residual turbulent eddying could also, on occasion, be observed in the cylinder. Furthermore, in some instances a smaller disc of frazil ice was observed to rise faster than a larger disc, contrary to expectations. In several cases, a smaller disc of frazil ice could be seen accelerating upward in the wake of a larger disc, probably because of pressure drag from the larger disc. The proximity of the cylinder wall, which was eventually lined with needle-ice crystals,

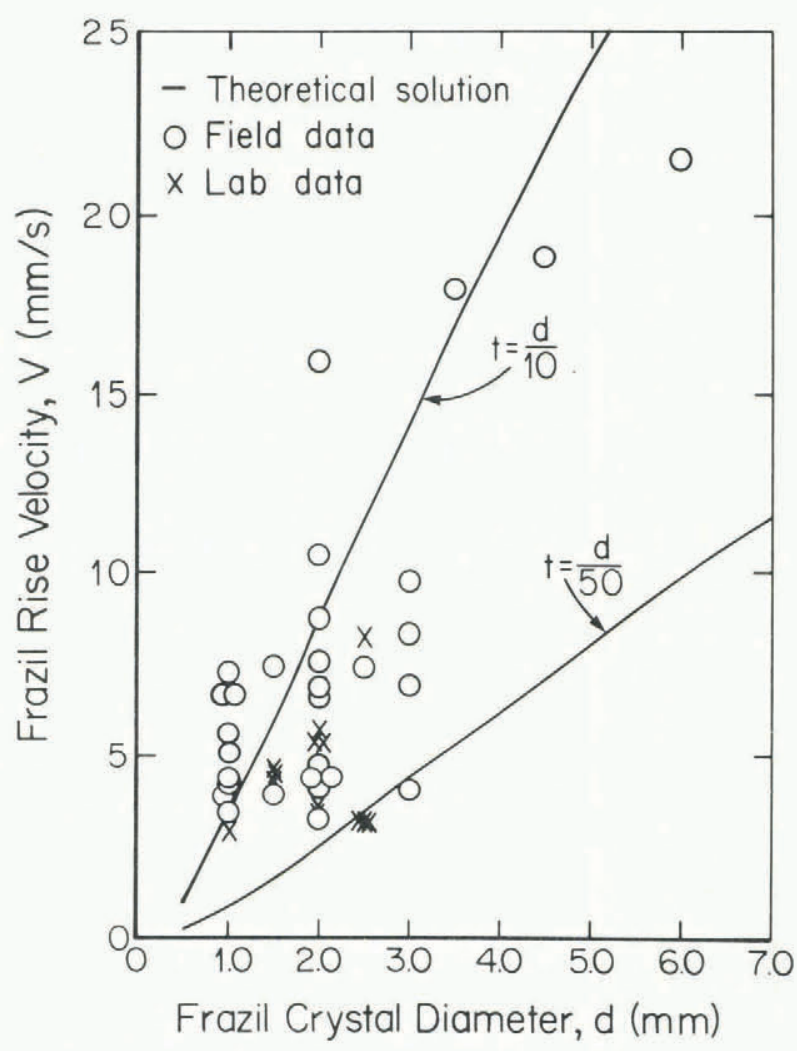

Fig.1. Measured and predicted frazil crystal rise velocity vs diameter.

could also affect the rise velocity of the frazil crystals.

Theoretical

Rise velocities of the frazil-ice crystals were predicted by a simple force balance model. The forces acting on the frazil-ice crystal are the upward net Archiniedes force and the retarding drag force. The force balance is

$$
\begin{aligned}
\rho_{i} \pi\left(d^{2} / 4\right) t a & =\left(\rho_{W}-\rho_{j}\right) \pi\left(d^{2} / 4\right) t g- \\
& -\left(\rho_{W} C_{D} V^{2} / 2\right)\left(\pi d^{2} / 4\right),
\end{aligned}
$$

where $\rho_{j}$ is the density of ice $\left(920 \mathrm{~kg} \mathrm{~m}^{-3}\right), \rho_{w}$ is the water density $\left(1000 \mathrm{~kg} \mathrm{~m}^{-3}\right)$, $d$ is the diameter of the frazil-ice crystal, $t$ is the thickness of the frazil-ice, a is the acceleration of the crystal, $g$ is the gravitational acceleration, $v$ is the rise velocity, and $C_{y}$ is the drag coefficient. Steadystate motion can be shown to be established within a very small distance equivalent to a few frazil disc thicknesses. The steady-state velocity of a frazil disc is given by

$$
v=\sqrt{2 g^{\prime} t / C_{D}},
$$

where $g^{\prime}=g\left(\rho_{W}-\rho_{j}\right) / \rho_{W}$ is the reduced gravitational acceleration.

Since the observed frazil ice diameters and rise velocities varied over a range of 1 to $6 \mathrm{~mm}$ and 3 to $22 \mathrm{~mm} \mathrm{~s} \mathrm{~s}^{-1}$, respectively, the corresponding Reynolds numbers for these experiments varied between 1 and 75. Here Reynolds number is defined as $\mathrm{Re}=\mathrm{Vd} / v$ and the water viscosity $v$ is assumed constant $\left(1.8 \times 10^{-6} \mathrm{~m}^{2} \mathrm{~s}^{-1}\right)$. According to Schlichting (1968) $C_{D}$ ranges between 24 and 1 for these Reynolds numbers. Furthermore, both Stokes's (1851) and Oseen's (1910) approximations for $C_{D}$ are inappropriate for $R_{e}>5$. Therefore, an empirical relation for the standard Re vs $C_{D}$ curve (e.g. see Schlichting 1968 or Willmarth 


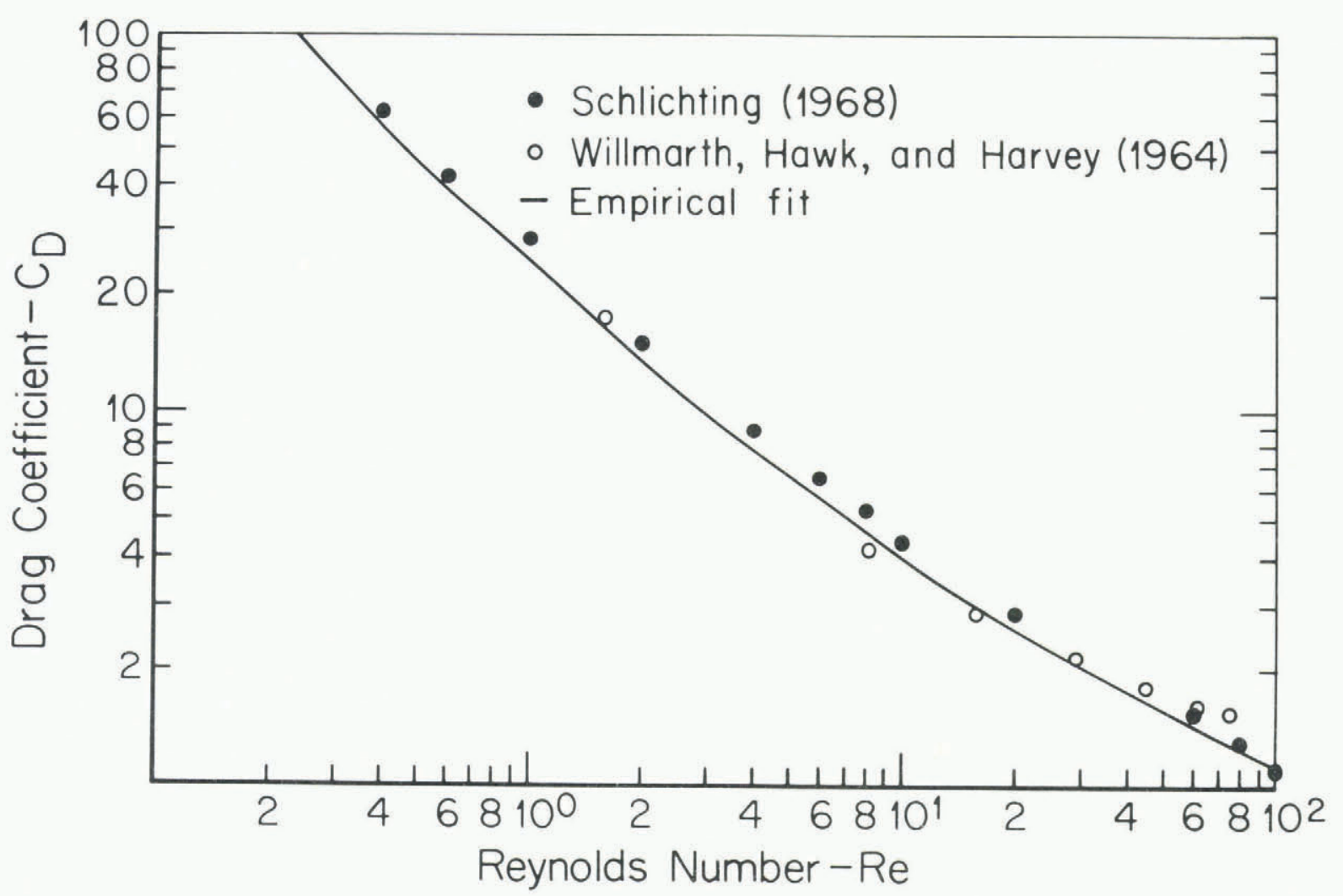

Fig.2. Enpirical fit of drag coefficient vs Reynolds numbers of frazil-ice crystals.

and others 1964) was determined to give a hest fit over the observed range of Reynolds numbers. This einpirical relation is

$\log C_{D}=1.386-0.892 \log R e+0.111(\log R e)^{2}$

and is depicted in Figure 2 together with the data of Schlichting (1968) and Willmarth and others (1964) for discs. There appears to be sone recent disagreement as to the "correct" values of $C_{D}$ for Reynoids numbers above 100 (e.g. see Stringham and others 1969, Boillat and Graf 1981), with the more recent measurements indicating slightly higher values of $C_{D}$. However, within the range $1<\operatorname{Re}<100$, the "standard" Re vs $C_{D}$ curve is well-accepted.

Equations (2) and (3) were solved for the thickness $t$ of the frazil-ice crystal in terms of the crystal diameter, i.e. $t=d / n$. Two sets of solutions of Equations (2) and (3) are shown in Figure 1 for the cases $n=10$ and $n=50$. These two cases form an envelope for the data on the measured velocity of frazil ice vs diameter of frazil-ice crystals. From the model, a characteristic thickness for the frazil crystals in these experiments appears to be about $t=d / 20$. Arakawa (1954) measured a rise velocity of $2 \mathrm{~mm} \mathrm{~s} \mathrm{~s}^{-1}$ for frazil crystals with $d=1 \mathrm{~mm}$. This velocity is predicted by the present model when a diameter-thickness ratio of 18 is assumed.

As the frazil-ice crystal rises through the supercooled water, the crystal grows due to the removal of the heat of fusion by convection. Since the rise velocity depends upon the crystal size, it is important to assess the effect of crystal growth rate upon the rise velocities measured in these experiments.

The semi-empirical model of Fernandez and Barduhn (1967) can be used to estimate the frazil crystal growth rate,

$$
v=a H^{1 / 2} \Delta T^{n},
$$

where $v$ is the growth rate in $\mathrm{cm} \mathrm{s}^{-1}, a$ and $n$ are experimentally determined constants, $\Delta T$ is the supercooling, and $\mathrm{W}$ is the shear velocity between the frazil crystal and the flow.

Fernandez and Barduhn's (1967) measurements of $n$ in Equation (4) indicate that $n$ is generally in the range $1.5<n<2.0$, contrasting with earlier studies in quiescent water (Hason 1952) where it was found that $n \approx 1.0$. It therefore appears that convective heat transfer, defined by Equation (4), is the maximum heat transfer mode when a shear velocity exists between frazil crystals and the flow. This suggests that whenever a shear velocity exists, frazil crystal growth by convective heat transfer will doininate other forms of growth.

Since $v$ is controlled by the convective transfer of heat from the stagnation line of the frazil disc to the flowing water, 14 should represent the veloc$i$ ty difference between the water and the frazil crystal. Tsang (1982[a]) suggests that if should be a function of turbulent intensity. However, this assumption contradicts models which successfully predict pollutant and aerosol deposition from turbulent flow on horizontal surfaces (Csanady 1973). In these models, particles are thought to move with the fluctuating turbulent eddies; the motion of the particle then consists of a slow vertical velocity ("free fall velocity") superimposed upon the turbulent velocity of the surrounding fluid. Accordingly, the buoyant velocity V, or the "free fall velocity", as given by Equation (2), is the maximum shear velocity $W$ between the frazil crystal and flowing water. Therefore, until the effects of turbulent intensity on growth rate are well established, we will assume that the maximun growth rate is dependent upon $\mathrm{V}$ and that $V=W$, and calculate the growth rate using $V$. For relatively large values of supercooling $(\Delta T=40 \mathrm{mK})$ and maximum measured velocity $\left(V=20 \mathrm{~mm} \mathrm{~s}^{-1}\right)$, Equation (4) predicts $\mathrm{v}<5.0 \times 10^{-3} \mathrm{~mm}^{-1}$. Since the observation period 
was about $10 \mathrm{~s}$, the increase in d of a $5 \mathrm{~mm}$ frazil crystal is $1 \%$ which corresponds to a change in V of $0.5 \%$. Therefore it should not be necessary to include the change in d in Equation (2) for these risevelocity experiments.

In deep rivers, the frazil crystal growth rate may be large enough to significantly increase $V$ and thus decrease the buoyancy time scale $\left(T_{B}=h / V\right)$. For example a $1 \mathrm{~mm}$ frazil crystal initially rising at about $5 \mathrm{~mm} \mathrm{~s}^{-1}$ in water with $\Delta T=50 \mathrm{mK}$ would require only $100 \mathrm{~s}$ to double in size. According to Equation (2) this would result in a $40 \%$ increase in $V$ and $a$ corresponding decrease of $30 \%$ in $T_{B}$. However, if $\Delta T=10 \mathrm{mK}, \mathrm{v}$ is an order of magnitude less, and the crystal would require $1000 \mathrm{~s}$ to double in size.

For the field experiments described below, $T_{B}$ was always $<50 \mathrm{~s}$ and $\Delta T<40 \mathrm{mK}$ so that it was not necessary to consider growth rate in these field studies.

\section{TURBULENT DIFFUSION TIME SCALE}

Vertical mixing in streams is a rapid process dependent upon the intensity of the turbulence. According to Taylor's (1921) diffusion model for turbulence (see also Monin and Yaglom 1965, Fischer and others 1979) the standard deviation of the spreading width of a disturbance is

$$
\sigma=\left(2 \mathrm{D}_{\top} \tau\right)^{1 / 2},
$$

where $D_{T}$ is the turbulent diffusion coefficient and $\tau$ is time. Integrating the standard effective viscosity distribution for a logarithmic velocity profile through the depth to obtain an average vertical diffusion coefficient gives

$$
\mathrm{D}_{\mathrm{T}}=0.067 \mathrm{hu}^{*} \text {, }
$$

where $u^{\star}$ is the friction velocity. Fischer and others (1979) show that the cross-stream distribution of a neutral tracer released at a wall is everywhere within about $3 \%$ of its mean value when the standard deviation of the tracer is equal to the cross-stream distance. Applying this principle to the vertical distribution of frazil crystals, we assume that the frazil crystals are completely mixed when the standard deviation of the spreading width is equal to the river depth. Then the time scale for complete vertical mixing through the depth is found by setting $\sigma=h$, which implies that

$$
T_{D}=h / 0.134 u^{\star} \text {. }
$$

COMPARISONS OF BUOYANT AND MIXING TIME SCALES Time scale ratio

since stream friction velocities are often in the range of 0.05 to $0.10 \mathrm{~m} \mathrm{~s}^{-1}$, the time scale for complete vertical mixing is of the same order of magnitude as the buoyancy time scale. The ratio

$$
T_{B} / T_{D}=0.134 u^{*} / \mathrm{V}
$$

is independent of flow depth. Furthermore, $u^{*}$ can be related to the mean river velocity $U$ by the Chezy coefficient $C$ yielding

$$
T_{B} / T_{D}=0.42 \mathrm{U} / C V \text {. }
$$

The time-scale ratio in the form of Equation (8) suggests that river slope is an important parameter in the determination of well-mixed vs layered flow. This corresponds to the observations in Hokkaido (Hirayama 1982) that surface accumulations of frazil ice would not occur for steeply sloping rivers. That is, $T_{B} / T_{D}$ increases as river slope increases, and for $T_{B} / T_{D}>1$ the time-scale ratio predicts well-mixed flow. The ratio in the form of Equation (9) empha-

sizes the importance of the river roughness or $C$. As roughness increases, $C$ decreases, and the time-scale ratio increases.

A measure of the time-scale ratio can be found if we assume a specific value for rise velocity $V$. The ratio gives a critical condition for frazil crystals of a particular diameter $d$ with velocity $V$. All smaller crystals will have a sinaller $V$, and therefore a larger value of $T_{B} / T_{D}$, and subsequently will remain well-mixed. Frazil crystals larger than d will form a stratified flow. Since observations of diameters of frazil-ice crystals in rivers are generally in the range of 0.1 to $5 \mathrm{~mm}$ (0sterkamp 1978, Osterkainp and Gusink in press), the appropriate choice of rise velocity to use in the time-scale analysis is probably close to $0.01 \mathrm{in} \mathrm{s}^{-1}$. This value is somewhat arbitrary and more research regarding the size and velocity distributions of frazil crystals is required to define a characteristic velocity more precisely.

With this value of $V$, the time-scale ratio from Equation (9) may be written

$$
T_{B} / T_{D}=42 \mathrm{U} / \mathrm{C},
$$

where $U$ is in $\mathrm{m} \mathrm{s}^{-1}$ and $C$ is in $\mathrm{m}^{1 / 2} \mathrm{~s}^{-1}$. Tsang (1982[b]) reports Chezy coefficients in the Beauharnois Canal along the Saint Lawrence Waterway less than $42 \mathrm{~m}^{1 / 2} \mathrm{~s}^{-1}$ and other estimates range between 30 and $40 \mathrm{mil}^{1 / 2} \mathrm{~s}^{-1}$. For this canal, assuming $C \approx 38 \mathrm{~m}^{1 / 2} \mathrm{~s}^{-1}$,

$$
T_{B} / T_{D}=1.1 \mathrm{U} \text {, }
$$

and for well-mixed flow, the criterion $T_{B} / T_{D}>1$ implies $U>0.91 \mathrm{~m} \mathrm{~s}^{-1}$, which is close to the rule-of-thumb value for the transition from layered to well-mixed frazil flow of $0.8 \mathrm{~m} \mathrm{~s}^{-1}$ accepted for the Saint Lawrence Waterway.

Similarly for Norwegian rivers, where $C$ may be chosen as $25 \mathrm{~m}^{1 / 2} \mathrm{~s}^{-1}$, which is appropriate for steep, shallow and rough rivers, the time-scale ratio gives $\mathrm{U}>0.60 \mathrm{~m} \mathrm{~s}^{-1}$, in agreement with the accepted rule-ofthumb value of $0.60 \mathrm{~m} \mathrm{~s}^{-1}$.

Matoušek (1982) has devised a formula for the critical velocity to maintain fully-mixed flow which also defines critical velocity in terms of $C$,

$$
U>0.064 \sqrt{\mathrm{C}(0.7 \mathrm{C}+6)} \mathrm{m} \mathrm{s}^{-1} \text {. }
$$

The llatousek formula yields high values of critical velocity, or, conversely, requires extremely low values of $C$ to match observed critical velocities. For example, $C=4.3 \mathrm{~m}^{1 / 2} \mathrm{~s}^{-1}$ is required to define the critical velocity of $0.60 \mathrm{~m} \mathrm{~s}^{-1}$ corresponding to Norwegian rivers. In contrast, the present formula predicts the observed critical velocities with a more reasonable value of $\mathrm{C}$.

\section{Present data}

Buoyant and turbulent diffusive time scales were calculated for two field sites during the initial frazil ice formation. The friction velocity $u^{*}$ was calculated from the water slope $S$ and hydraulic radius $R,\left(u^{*}=\sqrt{g S R}\right)$. The calculated values of friction velocity, buoyant time scale, turbulent diffusive time scale and time-scale ratio are listed in Table I.

\section{TABLE I. CALCULATION OF BUOYANT AND TURBULENT TIME} SCALES

Chatanika River Goldstream Creek

Surface slope

Mean width

Mean depth

Hydraulic radius

$\mathrm{u}^{*}=\sqrt{\mathrm{gSK}}$

$\mathrm{T}_{\mathrm{B}}=\mathrm{h} / \mathrm{V}$

$T_{D}^{B}=h / 0.134 u^{*}$

$T_{B} / T_{D}$

0.00235
$19.00 \mathrm{~m}$
$0.345 \mathrm{~m}$
$0.3329 \mathrm{~m}$
$87.5 \mathrm{~mm} \mathrm{~s}^{-1}$
$34.5 \mathrm{~s}$
$29.4 \mathrm{~s}$
1.2

0.0012

$8.00 \mathrm{~m}$

$0.40 \mathrm{~m}$

$0.3636 \mathrm{~m}$

$66.7 \mathrm{~mm} \mathrm{~s}^{-1}$

$40.0 \mathrm{~s}$

$44.8 \mathrm{~s}$

0.9 


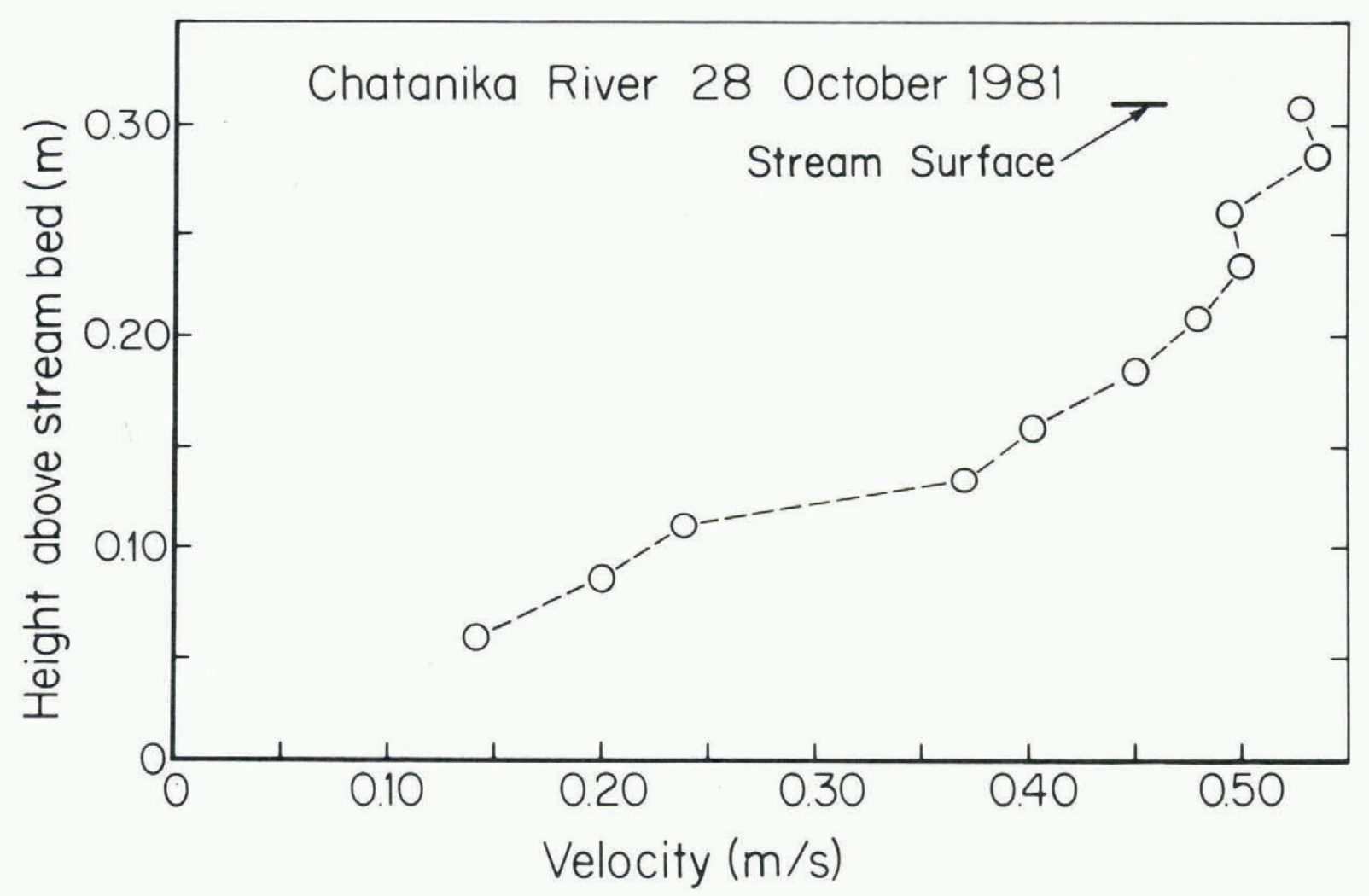

Fig.3. Measured velocity profiles in the Chatanika River, 28 october 1981.

Measured velocity profiles during the frazil formation and growth stage at the Chatanika River and the Goldstream Creek sites are depicted in Figures 3 and 4 respectively. Curve $A$ in Figure 4 is the measured velocity profile before frazil-ice production. The profile is typical of open channel flow, and fits a logarithmic curve with correlation coefficient of

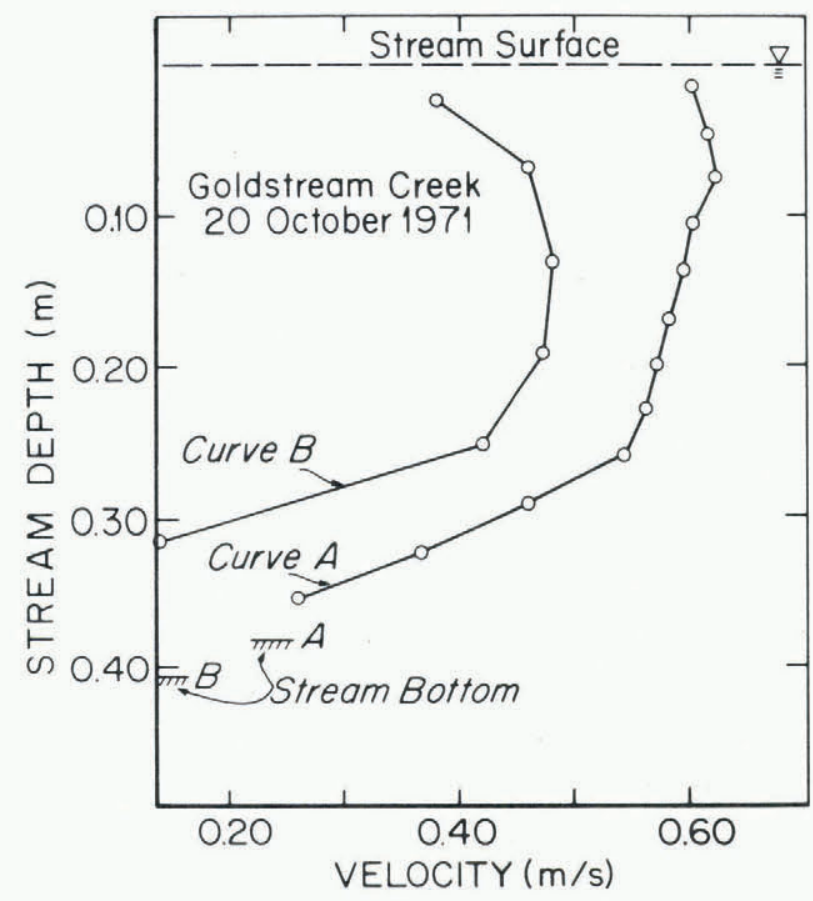

Fig.4. Measured velocity profile in Goldstream Creek, 20 October 1971.
0.96. The decelerated surface layer is relatively thin and represents a $3 \%$ velocity decrease from maximum. Curve $B$ was measured during the period of frazilice production. During this time the entire profile underwent a decrease in velocity, and the decelerated surface layer thickened to more than $25 \%$ of the depth. The surface velocity decrease was $20 \%$ of maximum velocity. Layering of the stream is consistent with an interpretation of a developing stratified frazilice layer as predicted by the $T_{B} / T_{0}$ criterion. This ratio is 0.9 in Goldstream Creek due to relatively slow mixing. In contrast, $T_{B} / T_{D}=1.2$ in the Chatanika River which is indicative of nore complete mixing. The corresponding velocity profile in Figure 3 could be fitted to a logarithmic curve with a correlation coefficient of 0.96 . Therefore, in these two instances the use of the time-scale ratio to determine wellmixed versus layered flow appears to be satisfactory. It should be noted that during the freeze-up, the slope of the river surface will change due to the growth of border and anchor ice, the formation of ice jams and subsequently changing backwater curves. Then, as $S$ decreases, the local value of $T_{B} / T_{D}$ also decreases until a slush-like frazil layer is formed. In contrast, in rapids or where $S$ remains high, the local value of $T_{B} / T_{D}$ will also remain high and implies that the flow will be well mixed.

SUMMARY

Rise velocities of frazil-ice crystals were measured in field and laboratory experiments. The rise velocities ranged from 3 to $22 \mathrm{~mm} \mathrm{~s}^{-1}$ for frazilice crystals with diameters of 1 to $6 \mathrm{~mm}$. A force balance model was derived which shows that rise velocities depend on the thickness of the frazil crystals. While the scatter in the experimental data was large, the model predicts rise velocities of the right order. For example, the rise velocities for frazil crystals $2 \mathrm{~mm}$ in diameter ranged from 3 to $16 \mathrm{~mm} \mathrm{~s}^{-1}$ while 6 arr $\mathrm{s}^{-1}$ was predicted by the model. A frazil-ice 
crystal diameter to thickness ratio of about 20 was obtained by comparing the model predictions to the experimental data.

A criterion for distinguishing between layered flow, where frazil accumulates on the stream surface, and well-mixed flow, where frazil becomes vertically mixed in the stream, was developed by comparing the buoyancy time scale $T_{B}$ with the vertical diffusive mixing scale $T_{D}$. This comparison suggests that when $T_{B} / T_{D}<1$ a layered flow will develop and when $T_{B} / T_{D}$ $>1$ a well-mixed flow will develop. The time-scale ratio $T_{B} / T_{D}$ was related to the mean stream velocity $U$ through the Chezy coefficient $C$. For the Saint Lawrence Waterway, the time-scale analysis for the transition to layered flow predicts $U \approx 0.91 \mathrm{~m} \mathrm{~s}^{-1}$ compared to the rule-of-thumb value of $U \approx 0.8 \mathrm{~m} \mathrm{~s}^{-1}$. For Norwegian rivers the predicted $U \approx 0.60 \mathrm{~m} \mathrm{~s}^{-1}$ is in agreement with the rule-of-thumb value.

Velocity profiles measured in Goldstream Creek showed a developing layered-flow structure during the formation of frazil ice. The value for $T_{B} / T_{D} \approx 0.9$ which predicts layered flow is in agreement with the observations. A velocity profile measured in the Chatanika River during a period of frazil-ice formation suggested a well-mixed flow in agreement with the calculated $T_{B} / T_{D} \approx 1.2$. These ratios were calculated with the rise velocity of frazil-ice crystals set somewhat arbitrarily at $0.01 \mathrm{~m} \mathrm{~s}^{-1}$. Further research is necessary to define this velocity more precisely.

Due to experimental difficulties, the reported measurements of the frazil-ice crystal rise velocities must be considered preliminary, the velocity profiles measured during periods of frazil-ice formation fragmentary and the rule-of-thumb criteria, for the transition from layered to well-mixed flow, crude. Nevertheless, the proposed theoretical criterion for this transition $\left(T_{B} / T_{D}>1\right)$ agrees with the present experimental evidence. This suggests that more systematic and detailed comparisons are warranted.

\section{ACKNOWLEDGEMENTS}

We wish to thank Mr R E Gilfilian and Mr V Gruol who helped to measure the velocity profiles and rise velocities of frazil-ice crystals under very difficult field conditions. This research was formerly supported by the US National Science Foundation, Earth Sciences Section, Grant GA-30748 and is now supported by the US Army Research Office.

\section{REFERENCES}

Arakawa K 1954 Studies on the freezing of water. 2. Formation of disc crystals. Joumal of the Faculty of Science, Hokkaido University Ser II 4(5): 311-339

Bengtsson L 1982 Experiences of the winter thermal regines of rivers and lakes with emphasis on Scandinavian conditions. In IAHR. Intemational Association for Hydraulic Research. International symposium on ice, Québec, Canada, 1981. Proceedings Vol 1: : 11-31

Boillat J L, Graf W H 1981 Settling velocity of spherical particles in calm water. Proceedings of the American Society of Civil Engineers. Journal of the Hydraulics Division 107(HY10): 1123-1131

Carstens T 1971 Heat exchanges and frazil formation. In IAHR. International Association for Hydraulic Research. Symposium on ice and its action on hydraulic stmuctures, Reykjavik, Iceland, 1970. Paper 2.11

Csanady G T 1973 Turbulent diffusion in the environment. Boston, MA, D Reidel

Fernandez R, Barduhn A J 1967 The growth rate of ice crystals. Desalination 3: 330-342

Fischer H B, List J E, Koh R, Imberger J, Brooks N H 1979 Mixing in inland and coastal waters. New York, Academic Press
Gosink J P, Osterkamp T E 1981 Hydraulic resistance generated by frazil ice formation. In Tsang $G$, Beltaos S (eds) Proceedings of workshop on hydraulic resistance of river ice... Burlington, Ontario...1980. Burlington, Ontario, Canada, Department of the Environment: 192-194

Hirayama K 1982 Hydraulic resistance of ice cover. In IAHR. Intermational Association for Hydraulic Research. International symposium on ice, Québec, Canada, 1981. Proceedings Vol 1: 224-237

Mason B J 1952 The spontaneous crystallization of supercooled water. Quarterly Joumal of the Royal Meteorological Society 78(335): 22-27

Matoušek V 1982 A mathematical model of the discharge of frazil in rivers. In IAHR. Intemational Association for Hydraulic Research. International symposium on ice, Québec, Canada, 1981. Proceedings Vol 1: 81-100

Monin A S, Yaglom A M 1965 Statisicheskaya gidromekhanika-mekhanika turbulentnosti. Moscow, Nauka [English translation: Statistical fluid mechanics: mechanics of turbulence Vol 2. Cambridge, MA, M.I.T. Press, 1975]

Oseen C W 1910 UUber die Stokessche Formel und über die verwandte Aufgabe in der Hydrodynamik. Arkiv för Matematik, Astronomi och Fysik 6(29)

0sterkamp T E 1978 Frazil ice formation: a review. Proceedings of the American Society of Civil Engineers. Joumal of the Hydraulics Division 104(HY9): 1239-1255

0sterkamp T E, Gosink J P In press. Selected aspects of frazil ice formation and ice cover development in turbulent streams. Proceedings of the Workshop on the hydraulics of ice-covered rivers, Edmonton, Alberta, June 1 st and 2nd, 1982

Schlichting H 1968 Boundary-layer theory. Sixth edition. New York, McGraw-Hill

Starosolszky O 1971 Ice in hydraulic engineering. Universitetet $i$ Trondheim. Norges Tekniske Hogskoze. Institutt for Vassbygging. Report 70-1

Stokes G G 1851 on the effect of the internal friction of fluids on the motion of pendulums. Transactions of the Cambridge Philosophical Society 9, Part II: 8-106

Stringham G H, Simons D B, Guy H P 1969 The behavior of large particles falling in quiescent liquids. US Geological Survey. Professional Paper 562-C

Taylor G I 1921 Diffusion by continuous movements. Proceedings of the London Mathematical Society Ser 2, 20(3): 196-211

Tsang G 1982[a] Frazil and anchor ice; a monograph. Ottawa, National Research Council Canada

Tsang G 1982[b] Resistance of Beauharnois Canal in winter. Proceedings of the American Society of Civit Engineers. Joumal of the Hydraulics Division 108 (HY2): $167-186$

Willmarth W W, Hawk N E, Harvey R L 1964 Steady and unsteady motions and wakes of freely falling disks. Physies of Fluids 7(2): 197-208 